Open Access

\title{
Transcription factor CREB3L1 mediates CAMP and glucocorticoid regulation of arginine vasopressin gene transcription in the rat hypothalamus
}

Mingkwan Greenwood ${ }^{1 *}$, Michael P. Greenwood ${ }^{1}$, Andre S. Mecawi ${ }^{2,3,4}$, Su Yi Loh³, José Antunes Rodrigues², Julian F. R. Paton ${ }^{5}$ and David Murphy ${ }^{1,3}$

\begin{abstract}
Background: Arginine vasopressin (AVP), a neuropeptide hormone that functions in the regulation of water homeostasis by controlling water re-absorption at kidneys, is synthesised in supraoptic nucleus and paraventricular nucleus of the hypothalamus. An increase in plasma osmolality stimulates secretion of AVP to blood circulation and induces AVP synthesis in these nuclei. Although studies on mechanism of AVP transcriptional regulation in hypothalamus proposed that CAMP and glucocorticoids positively and negatively regulate Avp expression, respectively, the molecular mechanisms have remained elusive. Recently, we identified CREB3L1 (CAMP-responsive element binding protein 3 like 1) as a putative transcription factor of Avp transcription in the rat hypothalamus. However the mechanism of how CREB3L1 is regulated in response of hyperosmotic stress in the neurons of hypothalamus has never been reported. This study aims to investigate effect of previously reported regulators (CAMP and glucocorticoid) of Avp transcription on transcription factor CREB3L1 in order to establish a molecular explanation for CAMP and glucocorticoids effect on AVP expression.

Results: The effect of CAMP and glucocorticoid treatment on Creb3/1 was investigated in both AtT20 cells and hypothalamic organotypic cultures. The expression of Creb3/1 was increased in both mRNA and protein level by treatment with forskolin, which raises intracellular CAMP levels. Activation of cAMP by forskolin also increased Avp promoter activity in AtT20 cells and this effect was blunted by shRNA mediated silencing of Creb3/1. The forskolin induced increase in Creb3/1 expression was diminished by combined treatment with dexamethasone, and, in vivo, intraperitoneal dexamethasone injection blunted the increase in Creb3/1 and Avp expression induced by hyperosmotic stress.
\end{abstract}

Conclusion: Here we shows that CAMP and glucocorticoid positively and negatively regulate Creb3/1 expression in the rat hypothalamus, respectively, and regulation of CAMP on AVP expression is mediated through CREB3L1. This data provides the connection between CREB3L1, a newly identified transcription factor of AVP expression, with the previously proposed mechanism of Avp transcription which extends our understanding in transcription regulation of Avp in the hypothalamus.

Keywords: Transcription, Forskolin, Dexamethasone, Hyperosmotic, Magnocellular neuron, Supraoptic nucleus, Paraventricular nucleus, AtT20, Rat, Organotypic culture

\footnotetext{
* Correspondence: mingkwan.greenwood@bristol.ac.uk

${ }^{1}$ School of Clinical Sciences, University of Bristol, Dorothy Hodgkin Building,

Whitson Street, Bristol BS1 3NY, England

Full list of author information is available at the end of the article
} 


\section{Background}

Expression of the gene encoding the neuropeptide hormone arginine vasopressin (AVP), which functions in water homeostasis, is found in the magnocellular neurons (MCNs) of supraoptic nucleus (SON) and paraventricular nucleus (PVN). The AVP prohormone is synthesised in the cell body and subsequently transported to the axon terminal in the posterior pituitary where it is stored [1]. Secretion is activated by hyperosmotic conditions through excitatory inputs from circumventricular organs [2, 3]. An increase of plasma osmolality activates secretion of AVP into the blood circulation to control water re-absorption at the kidney [4].

Whilst the regulation of $A v p$ gene expression in the hypothalamus has been studied for over three decades, ever since the cloning of the gene itself [5], the molecular details of the signaling and transcriptional mechanisms involved have remained elusive. That said, some evidence suggests that the cAMP/PKA pathway positively regulates expression of $A v p$, possibly through the phosphorylated cAMP responsive element-binding protein (CREB) $[6,7]$. An increase in cAMP and phosphorylated CREB was observed in the SON during osmotic stimulation [7, 8]. Activation of cAMP by forskolin (FSK; an adenylate cyclase activator) in dissociated hypothalamic primary culture, and treatment of fetal hypothalamic cultures with a protein kinase A activator, served to increase $A v p$ expression [6, 9]. Moreover the in vitro analysis of the rat $A v p$ promoter in the human choriocarcinoma cell line JEG-3 identified two cAMP responsive element (CRE)-sites (-227/-220 and -123/-116), and the expression of a dominant negative form of CREB decreased $A v p$ promoter activity, suggesting that the CREB protein regulates $A v p$ transcription [10]. However, the function of CREB as a transcription factor for $A v p$ was not confirmed in vivo [11]. In addition, a role for the immediate early gene Fos/Jun transcription factor family in Avp transcription has also been proposed through binding to an activator protein 1 (AP1) regulatory sequence in the Avp promoter [12-14].

On the other hand, glucocorticoids, the end product of hypothalamo-pituitary-adrenal axis, were shown to negatively regulate the expression of $A v p$ in the hypothalamus as part of a negative-feedback loop. Withdrawal of glucocorticoids by adrenalectomy results in increased $A v p$ mRNA expression in the PVN [15, 16], which can be reversed by glucocorticoid replacement [17]. There is also evidence supporting a role for glucocorticoids in the control of water homeostasis. In 2004, Durlo and colleagues reported increase of plasma corticosterone concentration, an event well known to occur in stress conditions, in response to hypervolemia and hyperosmolarity [18]. Moreover long-term hypoosmolality has been shown to increase glucocorticoid receptor expression in vasopressinergic MCNs of the SON, suggesting that glucocorticoids can inhibit AVP synthesis in response to osmotic cues [19]. In vitro promoter analysis studies have reported negative effects of glucocorticoid on $A v p$ promoter activity [10], but the regulatory mechanisms have been unclear.

Recently, we identified the basic leucine zipper transcription factor CREB3L1 (cAMP-responsive element binding protein 3 like 1; also called OASIS) as a putative transcriptional regulator of $A v p$ expression in the rat hypothalamus [20]. CREB3L1, an endoplasmic reticulum (ER) and Golgi-resident protein, is a transcription factor in CREB/ATF family. Its structure is similar to ER stress inducer ATF6 (Activating transcription factor 6) which contains $\mathrm{N}$-terminal activation, transmembrane and $\mathrm{C}$ terminal domains. CREB3L1 is activated by regulated intramembrane proteolysis, resulting in the release of an $\mathrm{N}$-terminal activating domain that is transported to the nucleus, where it regulates the transcription of target genes [21]. Activation of CREB3L1 was shown to be induced by ER stress in many physiological models but the mechanism of activation in neurons of the hypothalamus has never been reported.

Interestingly, cAMP was recently shown to activate expression of Creb3l1 in trophoblast cell line BeWo [22]. Thus in this study, we tested the hypothesis that expression of CREB3L1, a newly identified transcription factor of AVP may be regulated through cAMP pathway and glucocorticoid, the previously proposed regulators of AVP expression, and the effects of these regulators on AVP transcription may be mediated through CREB3L1 expression.

\section{Results}

\section{Effect of cAMP and glucocorticoid on Creb3/1 expression}

To investigate molecular details of the cAMP and glucocorticoid effects on Creb3l1 expression, we used the mouse pituitary AtT20 cell line as a model. The expression of Creb3l1 mRNA in AtT20 cells was investigated by qPCR. Treatment with cAMP activator $(10 \mu \mathrm{M}$ forskolin; FSK) increased Creb3l1 mRNA expression in a timedependent manner (Fig. 1a). This increase was maintained, although at a reduced level, at the $24 \mathrm{~h}$ time point. Immunoblotting also revealed an increase in CREB3L1 protein abundance following FSK treatment (Fig. 1b). Both the cleaved form and full length of CREB3L1 are clearly observed $2 \mathrm{~h}$ after FSK treatment, and levels of both increased in a time-dependent manner, in parallel with mRNA abundance. We also performed immunoblotting on fractionated cytosolic and nuclear extracts of AtT20 cells treated with FSK for $24 \mathrm{~h}$ (Fig. 1c). An increase of both forms of CREB3L1 was observed in the cytosolic portion of FSK-treated cells, with the cleaved form being majorly increased in the nuclear fraction. This suggests that 

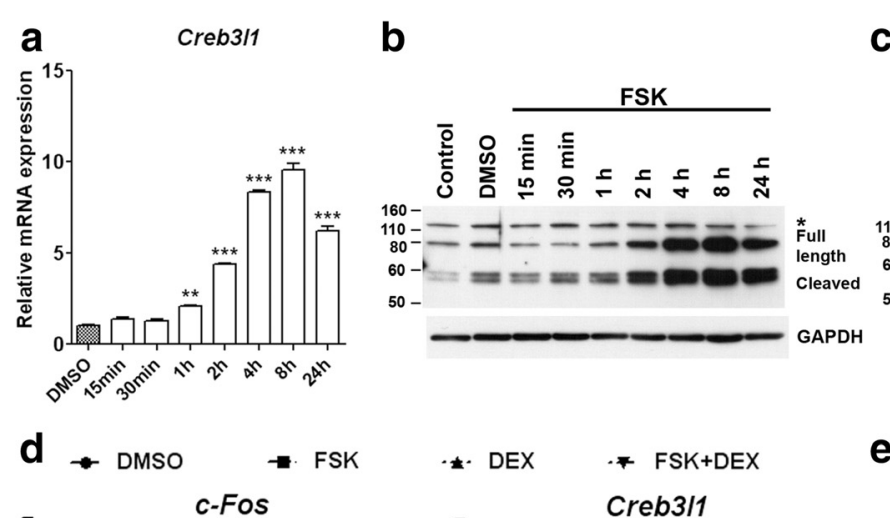

c
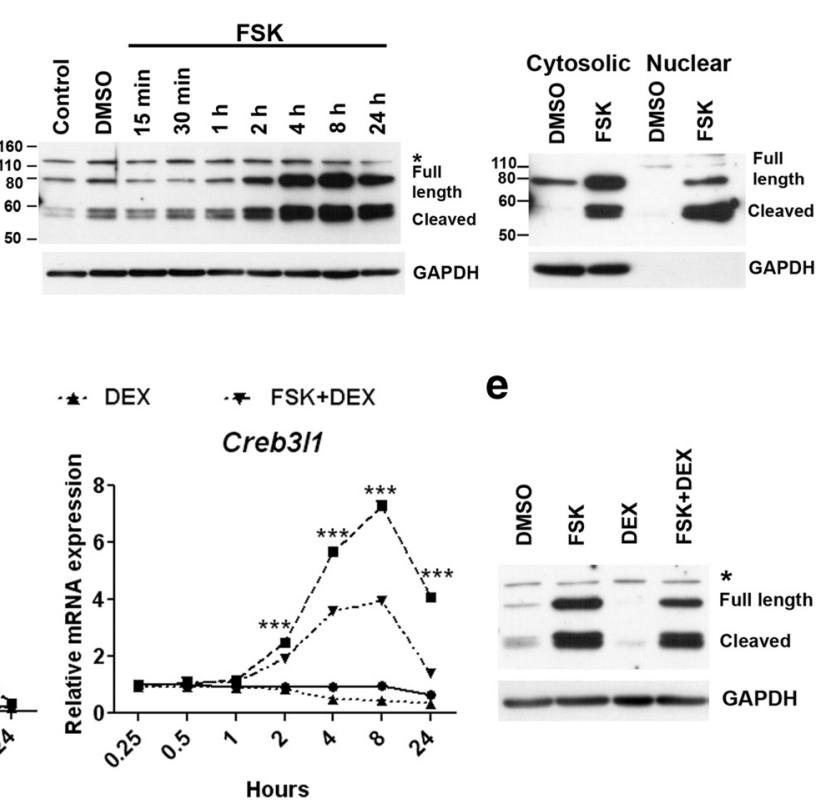

e
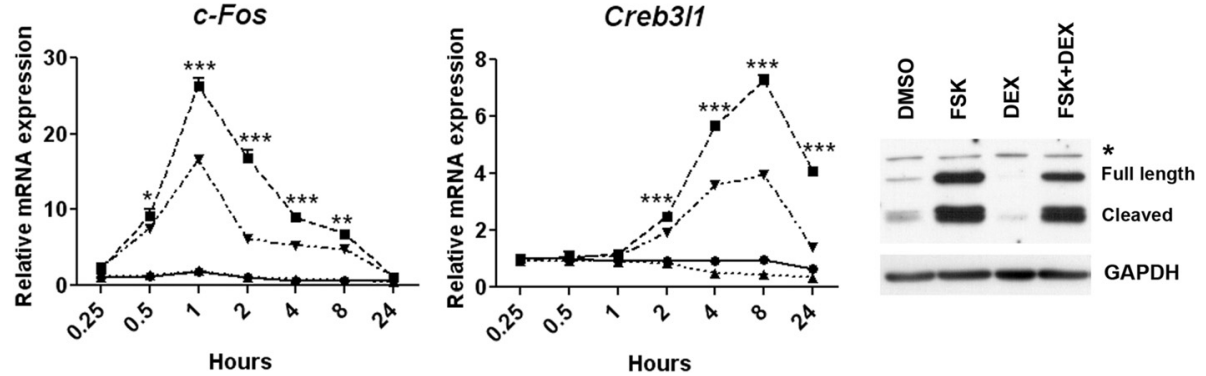

Fig. 1 CAMP and glucocorticoid regulate Creb3/1 expression. AtT20 cells were used to study regulation of Creb3/1. a-c AtT20 cells were treated with 10 MM FSK or vehicle (DMSO). a Creb3/1 mRNA expression was observed by qPCR at various time points ( $n=3$; One way ANOVA). b-c Immunoblotting was performed to examine protein expression level of CREB3L1 in both $\mathbf{b}$ total protein extracts and $\mathbf{c}$ cytosolic/nuclear extracts. $\mathbf{d}$-e AtT20 cells were treated with vehicle (DMSO), 10 MM FSK and/or 100nM DEX at various time points. $\mathbf{d}$ Effect of glucocorticoid on c-Fos and Creb3/1 expression was examined by qPCR ( $n=3$; Two way ANOVA). e Immunoblotting of CREB3L1 was performed at $24 \mathrm{~h}$ after treatment. GAPDH was used as an internal control for immunoblotting. * in B and E indicates non-specific band in immunoblotting. * in D indicate significant from FSK + DEX compared to FSK group. Scale bar, $20 \mu \mathrm{m}$; Error bar, +SEM; ${ }^{*}, p<0.05,{ }^{* *}, p<0.01 ; * * *, p<0.001$; FSK, forskolin; DEX, dexamethasone

the amount of CREB3L1 is increased following FSK treatment, and that the full-length protein is subsequently processed, with the $\mathrm{N}$-terminal active cleavage product being transported to the cell nucleus.

Next, the effect of glucocorticoid was investigated in AtT20 cells using a potent glucocorticoid medication, dexamethasone (DEX). We first characterized the effect of FSK and/or DEX on AtT20 cells using the expression of $c$-Fos, an immediate early gene that requires cAMP for activation [23], as a marker for cAMP activation (Fig. 1d). FSK treatment rapidly, but transiently, increased c-Fos mRNA levels. The maximal induction was reached at $1 \mathrm{~h}$, with levels returning to baseline by $24 \mathrm{~h}$. DEX treatment had no effect on basal c-Fos mRNA level but reduced the effect of FSK induction. DEX effects on Creb3l1 expression were investigated by qPCR (Fig. 1d). Treatment with DEX progressively decreased Creb3l1 mRNA expression under basal conditions. As before (Fig. 1a), FSK treatment increased Creb3l1 transcript abundance, while DEX attenuated this effect of FSK on Creb3l1 mRNA expression. CREB3L1 immunoblotting showed an increase of CREB3L1 following 24 h of FSK treatment. Lower levels of CREB3L1 were observed following DEX treatment compared to controls, and the combination of FSK and
DEX reduced CREB3L1 protein levels compared to FSK treatment alone (Fig. 1e).

\section{Effect of FSK and DEX treatment on Creb3/1 in organotypic cultures of rat hypothalamus}

To investigate the effect of cAMP and glucocorticoid on Creb3l1 expression in the neurons of hypothalamus, we investigated the effect of FSK and DEX in the organotypic culture extracted from rat hypothalamus (Fig. 2a). This model was successfully used to study activation of $A v p$ by cAMP [24]. Immunofluorescent staining using an antibody recognizing AVP NP-II confirmed the survival of AVP neurons in these cultures (Fig 2b). The effects of FSK and DEX treatments on Creb3l1 expression in the organotypic cultures were investigated by qPCR. Cultures were treated with FSK and/or DEX for 4 and $24 \mathrm{~h}$ (Fig. 2c). An increase in c-Fos expression was observed at the early time point of treatment $(4 \mathrm{~h})$, but not $24 \mathrm{~h}$, after FSK treatment. DEX had no significant effect on basal level of $c$-Fos mRNA at both time points; however it inhibited the effect of FSK-induced c-Fos expression at the $4 \mathrm{~h}$ time point. Creb3l1 expression increased following FSK treatment at both $4 \mathrm{~h}$ and $24 \mathrm{~h}$ time points. Interestingly, DEX treatment alone increased 
a
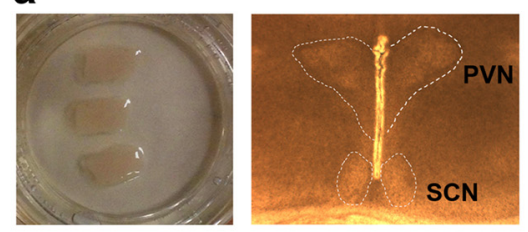

4 hours

C
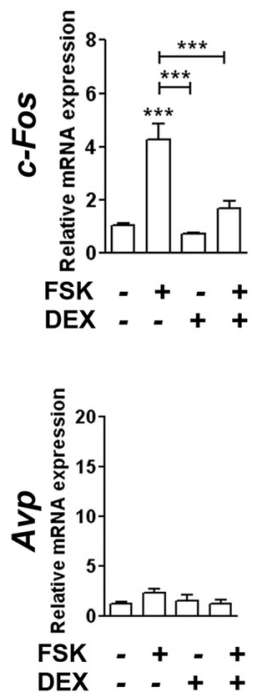
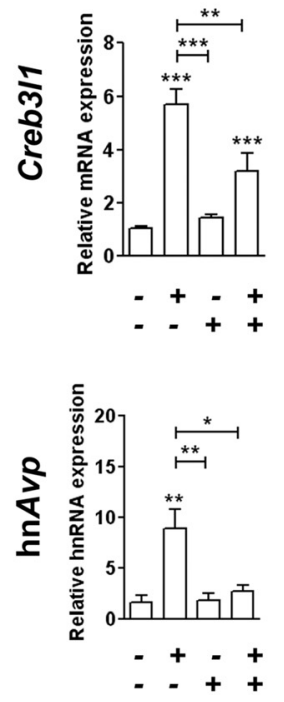

b

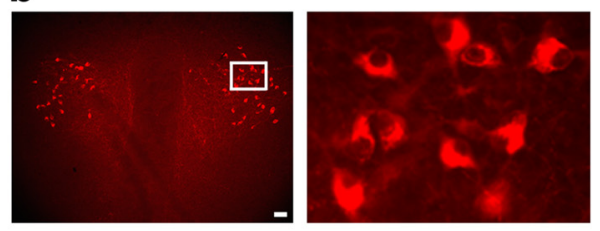

24 hours
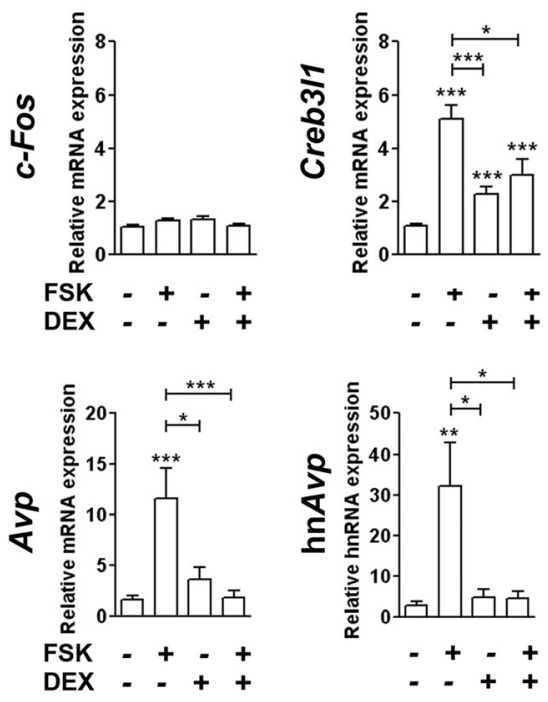

Fig. 2 Effect of CAMP activation and glucocorticoid in organotypic culture of rat hypothalamus. a Rat hypothalamic explants were cultured on Millicell membranes. An observation under bright field microscope showed the area of PVN and SCN are intact. $\mathbf{b}$ Immunofluorescent staining of AVP-NPII was performed at day 14 to demonstrate survival of vasopressinergic neurons in the culture. The high magnification image of the area in the box is shown. $\mathbf{c}$ The mRNA expression of hypothalamic explants in response to treatment of $10 \mu \mathrm{M}$ FSK and/or $100 \mathrm{nM}$ DEX for $4 \mathrm{~h}(\mathrm{n}=5$-7) and $24 \mathrm{~h}(n=8-15)$ was examined by qPCR. Scale bar, $100 \mu \mathrm{m}$; Error bar + SEM; ${ }^{*}, p<0.05 ;{ }^{* *}, p<0.01$; ${ }^{* * *}, p<0.001$ (One way ANOVA); FSK, forskolin; DEX, dexamethasone; PVN, paraventricular nucleus; SCN, suprachiasmatic nucleus. hnAvp, arginine vasopressin heteronuclear RNA

Creb3l1 expression at $24 \mathrm{~h}$, not the $4 \mathrm{~h}$ time point, but inhibited FSK-mediated induction. As expected, FSK treatment increased hnAvp levels, an effect also inhibited by DEX. Avp mRNA only increased at the $24 \mathrm{~h}$ FSK treatment, where DEX also inhibited the effect of FSK.

\section{Activation of CAMP pathways modulates Avp transcription through CREB3L1}

We asked if cAMP pathways could activate the Avp promoter in AtT20 cells. AtT20 cells were transfected with luciferase reporter gene plasmids containing $1 \mathrm{~kb}$ of the rat $A v p$ promoter, and then treated with FSK for $4 \mathrm{~h}$ and 24 h (Fig. 3a). Robust increases in luciferase activity were seen in FSK treated cells compared to vehicle controls at both time points with a slight decrease of activity at $24 \mathrm{~h}$ compared to $4 \mathrm{~h}$. Effect of DEX on AVP promoter activity was also investigated (Fig. 3b). Surprisingly we observed an increase of luciferase activity in response to DEX treatment and a combination of FSK and DEX treatment.

We then tested the hypothesis that the cAMP induced up-regulation of $A v p$ promoter activity is mediated by CREB3L1. To do this, Creb3l1-knockdown AtT20 cell lines were established by transduction of lentivirus containing Creb3l1 shRNA. Control cells expressed a nontargeting shRNA. The knockdown cells were selected using puromycin treatment. Successful knockdown was demonstrated at the Creb3l1 mRNA level by qPCR, and at the protein level by CREB3L1 immunoblotting (Fig. 3c). We then examined the effect of FSK treatments on Creb3l1 mRNA expression in the Creb3l1 knockdown cell line (Fig. 3d). The results showed that, from its diminished baseline, Creb3l1 mRNA increased in abundance in response of FSK, suggesting that the knockdown cell line is still able to respond to FSK, but the level of Creb3l1 mRNA expression is massively reduced compared to the control shRNA cell line. We then transfected the Creb3l1 knockdown AtT20 cells with the luciferase reporter gene plasmids containing $1 \mathrm{~kb}$ of the $A v p$ promoter, and asked about the response to FSK (Fig. 3e). Whilst FSK treatment robustly increased luciferase activity driven by the $1 \mathrm{~kb}$ $A v p$ promoters in the control non-targeting shRNA cell line, knockdown of Creb3l1 substantially diminished this effect, strongly suggesting that the effect of FSK-induced activation of the Avp promoter is mediated by Creb3l1. 


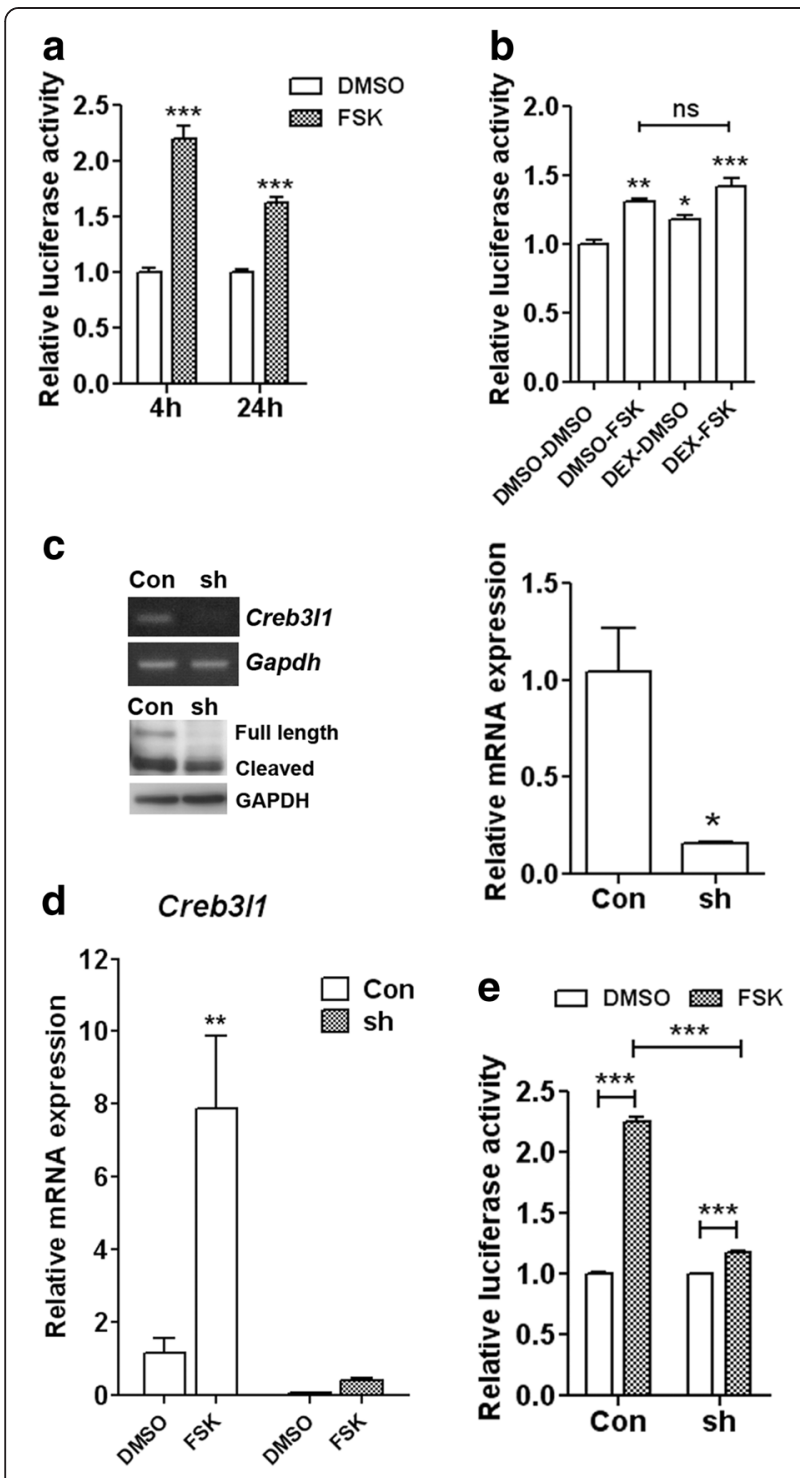

Fig. 3 CAMP-activated AVP promoter activity is modulated through Creb3/1. a-b AtT20 cells were transfected with 1 kb rat Avp promoter construct. At $24 \mathrm{~h}$ after transfection the cells were a treated with 10 MM FSK for 4 and 24 h or $\mathbf{b}$ pre-treated with 100nM DEX or DMSO for $2 \mathrm{~h}$ and followed by $4 \mathrm{~h}$ treatment of $10 \mu \mathrm{M}$ FSK or DMSO and luciferase activity was measured $(n=3)$. c-e The Creb3/1-knockdown AtT20 cell line was produced in parallel with a control non-targeting shRNA cell line by transduction of lentivirus containing Creb3/1 or control non-targeting shRNA and further selected with puromycin. c The level of Creb3/1 knockdown was investigated by qPCR and immunoblotting in the AtT20 shRNA cell lines $(n=3)$. $\mathbf{d}$ The effect of FSK on Creb3/1 mRNA expression was examined by qPCR in control non-targeting and Creb3/1 knockdown cell lines $(n=3)$. e Luciferase assays were performed in control and Creb3/1-knockdown cell lines using $1 \mathrm{~kb}$ Avp promoter construct driving luciferase reporter gene $(n=3-4)$. Error bar + SEM; ${ }^{*}, p<0.05 ;{ }^{* *}, p<0.01 ;{ }^{* * *}, p<0.001$ (Two way ANOVA for A, D and E, One way ANOVA for B and independent sample unpaired Student's t-tests for C). FSK, forskolin; Con, Control; sh, shRNA; h, hour; ns, no significant difference

\section{Creb3/1 expression in the male rat PVN and SON in} response to acute hyperosmotic stress

In vitro study showed that Creb3l1 expression significantly increased at $1 \mathrm{~h}$ after FSK treatment (Fig.1a). To examine how quick the activation of Creb3l1 expression occur in the rat PVN and SON, acute hyperosmotic stress was induced by intraperitoneal (i.p) injection of hypertonic saline (1.5 M, $1.5 \mathrm{ml} / 100 \mathrm{~g}$ of body weight). Hyperosmotic stimulation has previously shown to increase cAMP level in the SON [8]. The expression of c-Fos mRNA, a marker for neuronal activity which is also a cAMP-responsive gene, was investigated by qPCR to demonstrate activation of the PVN and SON in response to this stimuli (Fig. 4a). The abundance of the $c$ Fos mRNA increased very rapidly (10 $\mathrm{min})$ after injection, and levels progressively increased until peaking at $60 \mathrm{~min}$. This was followed by a decline in both PVN and SON. A higher degree of increase of $c$-Fos was observed in SON compared to PVN. At $60 \mathrm{~min}$, the point at which $c$-Fos mRNA levels peaked, a statistically significant increase in Creb3l1 mRNA levels was observed. However, in contrast with $c$-Fos, levels did not thereafter decline; rather, the abundance of Creb3l1 mRNA progressively increased until the end of the experiment $(4 \mathrm{~h})$. A higher level of Creb3l1 mRNA expression was observed in the PVN compared to the SON (Fig. 4a). Immunostaining of CREB3L1 was performed in rat PVN and SON following hyperosmotic stress to investigate CREB3L1 expression and localization (Fig. 4b). Compared to the controls injected with isotonic saline, rats injected i.p. with hypertonic saline showed a higher level of CREB3L1-like material in both PVN and SON (4 h after injection). The high magnification confocal microscope images showed increased CREB3L1-like material, together with a change in localisation from the perinuclear area in isotonic controls, to cytoplasmic and nuclear staining in hypertonic injection, as previously observed following chronic osmotic stimulation [20].

\section{Glucocorticoids inhibit Creb3/1 and Avp expression in rat hypothalamus}

To investigate glucocorticoid actions on Creb3l1 and Avp gene expression in vivo, rats were injected with DEX before injection of isotonic or hypertonic saline (Fig. 5). At $4 \mathrm{~h}$ after saline injection, mRNA expression levels were examined in the PVN and SON. As expected, Creb3l1 mRNA increased in response of hypertonic saline in both PVN and SON. DEX injection reduced hypertonicinduced Creb3l1 mRNA expression in both PVN and SON compared to vehicle controls. Both basal and hypertonic-stimulated $\mathrm{hn} A v p$ expression was diminished by pretreatment with DEX in PVN and SON. DEX also decreased hypertonic stimulation of $A v p$ mRNA in PVN and SON. 


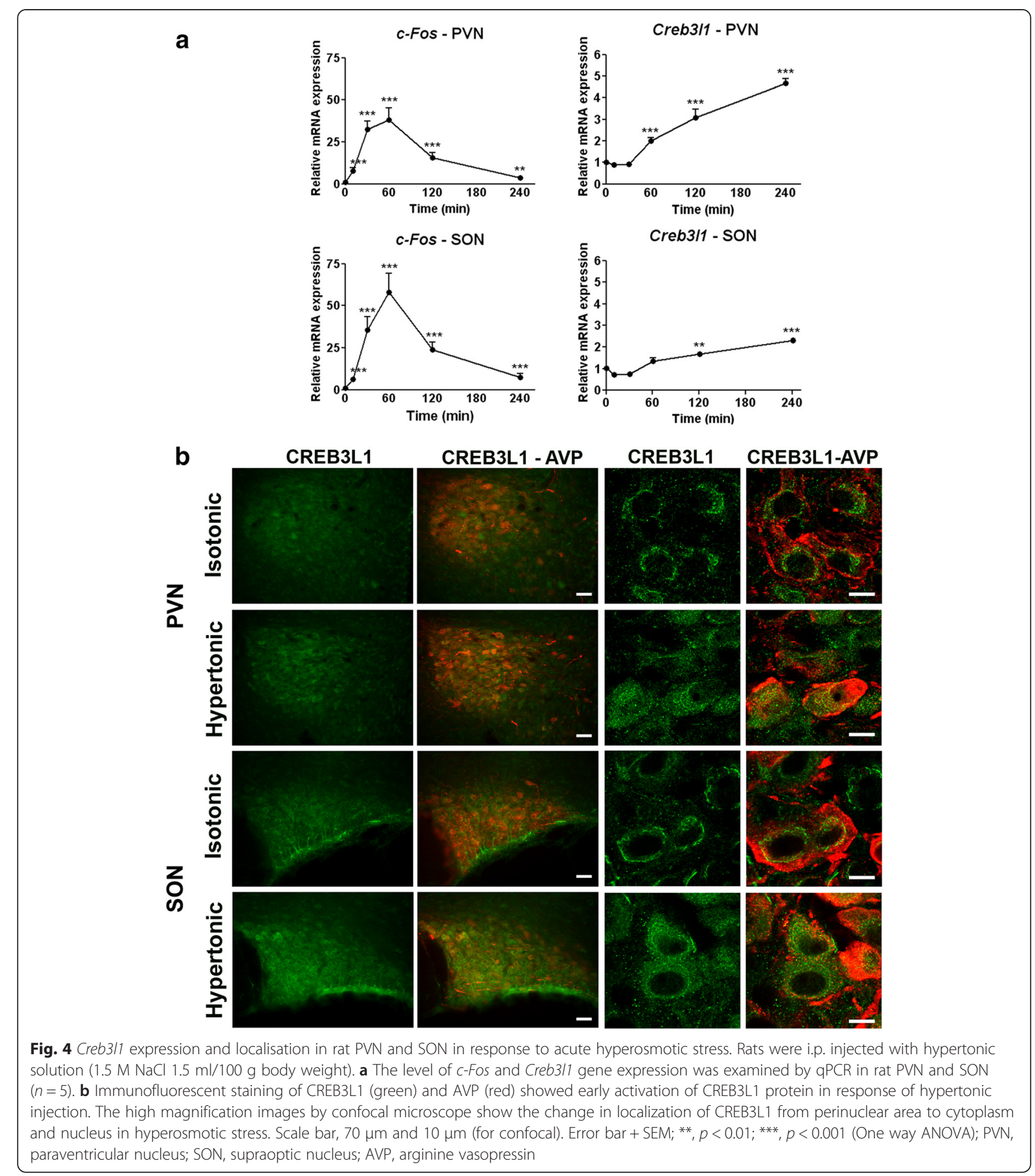

\section{Discussion}

We recently identified CREB3L1 as a transcription factor capable of regulating Avp gene expression in the rat hypothalamus in response to the chronic hyperosmotic stressors of dehydration ( 1 and 3 days) and salt loading (1 and 7 days) [20]. However the connection between this newly identified transcription factor and the previously proposed mechanism of AVP transcription was unknown. Here we show that cAMP and glucocorticoids, regulators of $A v p$ expression, similarly regulate Creb3l1 expression. Importantly, we show that CREB3L1 mediates cAMP-induced $A v p$ expression, which is subject 


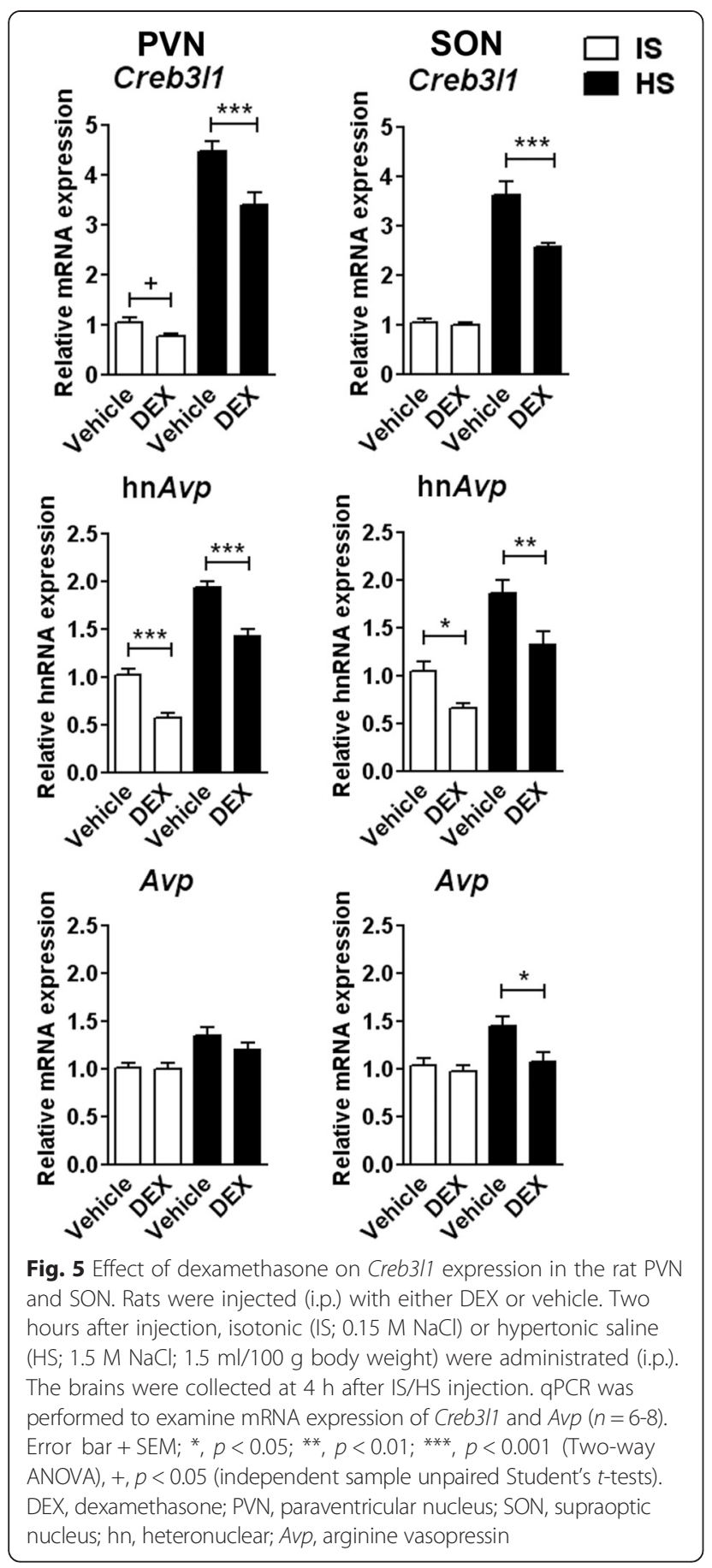

to glucocorticoid inhibition. Therefore this study provides the link between CREB3L1 and previously proposed mechanism of AVP transcription.

An increase in cAMP has previously been reported in response of hyperosmotic stress in the PVN and SON [8]. There is some evidence showing that Avp expression is activated through cAMP pathways $[6,10,25,26]$. To investigate the control of Creb3l1 expression, and its relationship to Avp transcriptional control, AtT20 cells, which endogenously express Creb3l1, were used as a model. The expression of Creb3l1 in these cells responded robustly to activation of cAMP by FSK treatment, with mRNA expression increasing after $1 \mathrm{~h}$, similar to that observed following i.p. hypertonic saline administration in the rat. CREB3L1 protein levels also increased following FSK treatment, in parallel with the mRNA encoding it.

To confirm an effect of cAMP on Creb3l1 expression in the hypothalamus, we used hypothalamic organotypic cultures to study Creb3l1 expression in response to activation of cAMP pathways. Increase of $A v p$ mRNA in response to FSK treatment was previously shown in this system [25]. The robust increase in Creb3l1 expression induced by FSK confirmed responsiveness to cAMP pathways. The increase in hnAvp but not Avp mRNA after $4 \mathrm{~h}$ FSK treatment is consistent with many previous reports of $A v p$ hnRNA being a sensitive measure of transcriptional activity for this gene [27, 28], without necessarily affecting the large pool of steady-state mature $A v p$ mRNA. No activation of $c$-Fos expression at $24 \mathrm{~h}$ when $A v p$ expression is still elevated is consistent with the previously proposed hypothesis by Arima and colleagues that $c$-Fos may be involved but is not essential for the induction of Avp transcription [29].

cAMP activation of AVP transcription is believed to be mediated by phosphorylation of CREB by PKA $[6,7]$. However, a role for phosphorylated CREB in the control of $A v p$ expression in an in vivo context has not been substantiated [11]. The shRNA-mediated Creb3l1 knockdown reduced promoter activity, suggesting that cAMPinduced Avp transcription is in fact mediated by Creb3l1. To our knowledge no evidence of a relation between CREB3L1 and phosphorylated CREB has been reported; however a study in a trophoblast cell line proposed that cAMP-induced activation of Creb3l1 is mediated by p38MAP kinase pathway [22]. The later induction of Creb3l1 mRNA expression relative to the cAMP inducible immediate early gene c-Fos, both in vitro and in vivo, certainly suggests the involvement of an intermediary factor, potentially a transcription factor, though this remains to be determined. Furthermore, the previous studies on CREB3L1 also reported that CREB3L1 is activated by ER stress in several models [30-33]. Although we previously reported function of CREB3L1 in regulation of ER stress response genes in rat hypothalamus during hyperosmotic challenge [34], activation of CREB3L1 expression itself by ER stress has never been reported in the hypothalamic neurons.

To examine the dynamic changes in gene expression that govern the hypothalamic response to a hyperosmotic cue, we exploited the acute stimulus of i.p. administration of a hypertonic saline solution. As expected, expression of $c$-Fos, a cAMP-responsive immediate early gene, rapidly increased in both PVN and SON, peaking 
at $1 \mathrm{~h}$ and declining thereafter toward basal levels. The activation of Creb3l1 transcription was slower than that of $c$-Fos, but unlike $c$-Fos, continued to increase from $1 \mathrm{~h}$ onwards. We, and others, have reported that hnAvp expression increases as early as $10 \mathrm{~min}$ and reaches a peak $30 \mathrm{~min}$ after hypertonic saline administration $[35,36]$. This means that the increase in hnAvp transcription precedes the activation of Creb3l1 mRNA expression in the PVN and the SON, as observed in the present study. Such a rapid increase in hnAvp expression implies that new protein synthesis may not be necessary to achieve this early response. We previously reported that CREB3L1 protein expression was most abundant in the Golgi of MCNs in euhydrated rats [20]. When it is activated, CREB3L1 is rapidly cleaved by regulated intramembrane proteolysis. The released $\mathrm{N}$-terminal domain of the protein then enters the nucleus to regulate transcription of target genes [21]. One may speculate that the localisation of CREB3L1 in the Golgi of euhydrated rats supports a role for pre-existing CREB3L1 protein in the early activation of $\mathrm{hn} A v p$ transcription. A change in cellular and subcellular localisation of CREB3L1 was indeed evident $4 \mathrm{~h}$ after initiation of hyperosmotic stress (Fig. 4b), similar to our previous findings at the longer time point of 3 day dehydration [20]. Moreover, previous study in C6 glioma cells showed that ER stress inducer dithiothreitol can activate CREB3L1 at the protein level, while the mRNA level is unchanged. An activation signal was demonstrated to increase CREB3L1 stability by inhibiting degradation by the proteasome system [37]. Such a mechanism may facilitate the early function of CREB3L1 in the regulation of $A v p$ transcription. Further investigation is needed to address this issue in the PVN and SON.

Inhibition of $A v p$ expression by glucocorticoids has been described for many years, although the molecular mechanisms have remained unclear. Putative glucocorticoid responsive element (GRE) sites were identified in the rat and bovine $A v p$ promoters (-622/-608 and within -300 to -155 , respectively) $[38,39]$, but were not tested functionally. However, the promoters of many genes that are negatively regulated by glucocorticoids do not contain GRE sites, suggesting that the regulatory mechanisms of glucocorticoids are not only mediated by direct binding of glucocorticoid receptor to a GRE. The interaction of glucocorticoid receptor with transcription factors or cofactors is also believed to be a regulatory mechanism of glucocorticoids [40]. Here we show that DEX treatment inhibits both basal and FSK-stimulated Creb3l1 expression in AtT20 cells. In organotypic cultures, DEX treatment inhibited FSK-induced $A v p$ expression, in line with previous reports [24], and also FSK-induced Creb3l1 expression, similar to our findings in AtT20 cells.

We were surprised that DEX treatment increased Avp promoter activity in AtT20 cells, disagreeing with previous studies in hypothalamic neuronal cells and human choriocarcinoma cell line JEG-3 that showed DEX treatment inhibits $A v p$ promoter activity [10, 41]. AtT20 cells express glucocorticoid receptors [42] and activation of these receptors can positively and negatively regulate gene expression via the direct binding onto DNA or through direct protein-protein interaction [43]. One possibility is that DEX may alter other genes that influence $A v p$ promoter activity in AtT20 cells that do not express Avp. This represents a limitation of performing promoter studies in AtT20 cells.

We next tested if peripheral administration of DEX in the animal could inhibit $A v p$ and/or Creb3l1 stimulation by hypertonic saline. Indeed, a single injection of DEX significantly diminished hypertonic-induced increases in hnAvp and Creb3l1 expression in both PVN and SON. In agreement with DEX inhibition of $A v p$ in PVN, withdrawal of glucocorticoids in the rat by adrenalectomy results in increased expression of $A v p$ in PCNs, but not MCNs, and this effect can be reversed by administration of DEX or corticosterone $[15,17]$. It is interesting that we observed a clear DEX inhibition of $A v p$ expression in the whole PVN. Studies of glucocorticoid regulation in the PVN have largely opted for in situ hybridization rather than qPCR to measure $A v p$ expression specifically in PCNs $[15,17,44]$. This approach prevents the large pool of $A v p$ in MCNs masking the changes in gene expression in the smaller population of PCNs. However, our finding of DEX inhibition of $A v p$ expression in both PVN and SON support the concept of DEX modulation of $A v p$ expression may not only be evident in PCNs, but also in $\mathrm{MCNs}$ consistent with proposed functions of glucocorticoids in the control of water homeostasis [45]. It is known that modulation of excitatory and inhibitory synaptic transmission by glucocorticoids in the mouse PVN and SON is lost with conditional deletion of the glucocorticoid receptor [46]. However, the role of the glucocorticoid receptor on this DEX-induced regulation of Creb3l1 expression in MCNs is not known. Therefore, our finding in AtT20 cells, organotypic cultures, and in vivo study suggest that DEX modulation of Avp expression is perhaps mediated through DEX-regulation of Creb3l1 expression.

\section{Conclusion}

In the long history of the characterisation of the regulatory mechanisms controlling expression of $A v p$, it has become accepted that the CAMP/PKA pathway is a major positive regulator for $A v p$ transcription, whilst glucocorticoids have an inhibitory effect, but the molecular pathways mediating these effects have remained largely elusive [40]. Here, we provide evidence that Creb3l1 is regulated by cAMP and glucocorticoids, and that this transcription factor may mediate the effects of these signaling pathways on Avp expression. 


\section{Methods \\ Animals}

Male Sprague-Dawley rats weighing 250-300 g were used in this study. Rats were housed at a constant temperature of $22{ }^{\circ} \mathrm{C}$ and a relative humidity of $50-60 \%(\mathrm{v} / \mathrm{v})$ under a 14:10 h light/dark cycle. The rats were given free access to food and tap water, unless stated. Animal experiments were performed between $9 \mathrm{am}-2 \mathrm{pm}$. All experiments were performed under a Home Office UK licence held under, and in strict accordance with, the provision of the UK Animals (Scientific Procedures) Act (1986); they had also been approved by the University of Bristol Animal Welfare and Ethical Review Board.

\section{Hypertonic stress experiment}

To induce acute hyperosmotic stress, a single i.p. injection of $1.5 \mathrm{ml} / 100 \mathrm{~g}$ body weight of $1.5 \mathrm{M} \mathrm{NaCl}$ solution was performed. For gene expression study, rats were randomly allocated into 1 of 6 groups, control, $10 \mathrm{~min}$, $30 \mathrm{~min}, 1,2$, and 4 hours (h) after administration of hypertonic saline. To investigate actions of glucocorticoid on gene expression in the hypothalamus, rats were injected i.p. with $0.5 \mathrm{ml} 0.15 \mathrm{M} \mathrm{NaCl}$ (vehicle) or $0.5 \mathrm{ml}$ of $1 \mathrm{mg} / \mathrm{kg}$ body weight dexamethasone (DEX; Sigma D2915) $2 \mathrm{~h}$ before Isotonic $(0.15 \mathrm{M} \mathrm{NaCl}$ solution; $1.5 \mathrm{ml} / 100 \mathrm{~g}$ body weight) or hypertonic saline injection. After injection of hypertonic or isotonic saline rats were placed back in their home cages for $4 \mathrm{~h}$, and water, but not food, was removed for the duration of the experiment. For RNA analyses, rats were killed by striking of the cranium, followed by decapitation, using a guillotine (Harvard Apparatus). Brains were removed and frozen on dry ice before being stored at $-80{ }^{\circ} \mathrm{C}$. For immunofluorescent study, rats were i.p. injected with hypertonic saline for $4 \mathrm{~h}$. Isotonic saline solution was injected for the control group.

\section{Organotypic culture of rat hypothalamus}

Organotypic cultures were performed following the protocol previously described [47]. Sprague-Dawley pups (P5P7) were purchased from Harlan Laboratories (UK). Pups were decapitated using scissors, and brains were removed and incubated in cold-Hank's solution for $5 \mathrm{~min}$, and then dissected using the optic chiasm as a landmark to produce a hypothalamic block. The block was placed onto a Mcllwain Tissue Chopper and $400 \mu \mathrm{m}$ sections containing the PVN were cut then transferred to ice-cold Hank's solution and incubated for $1 \mathrm{~h}$ before being placed onto a Millicell Cell Culture Insert (30 mm, hydrophilic PTFE, $0.4 \mu \mathrm{m}$; Millipore PICM03050) in a 6-well tissue culture plate with $1.1 \mathrm{ml}$ of culture medium. The culture sections were incubated at $37{ }^{\circ} \mathrm{C}, 5 \%$ (v/v) $\mathrm{CO}_{2}$ for 14 days before performing an experiment. The culture medium was replaced with fresh media every 2 days, and 4 days before the experiment the medium was replaced with serum-free medium. For treatments, culture medium was replaced with serum-free medium containing $10 \mu \mathrm{M}$ FSK (Sigma) and/or 100nM DEX. At appropriate time points, the membrane was frozen on dry ice, and then the PVN was punched out using a $1 \mathrm{~mm}$ diameter micropunch (Fine Scientific Tools). The punched tissue was dispersed into a $1.5 \mathrm{ml}$ tube for RNA extraction using Qiazol Reagent with the Qiagen RNeasy kit as described below.

\section{Cells and treatments}

AtT20/D16v-F2 cells (Sigma; 94050406) were cultured in DMEM (Sigma; D6546) supplemented with $10 \%$ (v/v) heat-inactivated fetal bovine serum (Gibco), $2 \mathrm{mM}$ L-glutamine and $100 \mathrm{unit} / \mathrm{ml}$ of penicillin-streptomycin. Cells were incubated at $37{ }^{\circ} \mathrm{C}$ in a humidified incubator with $5 \%(\mathrm{v} / \mathrm{v}) \mathrm{CO}_{2}$. For chemical treatments, cells were seeded onto tissue culture plates to 60-70 \% confluence. After $18-24 \mathrm{~h}$, the culture medium was replaced with medium containing $10 \mu \mathrm{M}$ FSK (Sigma) and/or 100nM DEX.

To produce a Creb3l1 knockdown cell line, AtT20 cells were transduced with a lentivirus containing shRNA targeting mouse Creb3l1. The Creb3l1 shRNA sequence (CGGCTCAATGACTGTGAAAGA) was obtained from the RNAi consortium shRNA library. Sense and antisense oligonucleotides for shRNAs were synthesised (European MWG Operon) and cloned into lentiviral transfer vector pLKO.1 puro according to manufacturer's guidelines (pLKO.1 puro was a gift from Bob Weinberg, Addgene plasmid 8453). A non-targeting shRNA sequence (ATC ATGTTAGGCGTACGGACT) was used as a control. Virus particles were produced as previously described [20]. Twenty four hours after transduction, puromycin (2 $\mu \mathrm{g} / \mathrm{ml}$, Life technologies) was added to cell culture medium. The cells were cultured in presence of puromycin for two weeks before use in experiments. The level of knockdown was confirmed by quantitative PCR (qPCR) and immunoblotting of CREB3L1 (see below).

\section{RNA extraction and CDNA synthesis}

Frozen brains were sliced into $60 \mu \mathrm{m}$ coronal sections in a cryostat. Sections were mounted on glass slides and stained with $0.1 \%(\mathrm{w} / \mathrm{v})$ toludine blue/70 \% ethanol then visualised on a light microscope until brain nuclei were visible, then PVN and SON samples were collected using a $1 \mathrm{~mm}$ micropunch. The optic chiasm (SON), or neurons staining at the PVN location lateral to the third ventricle $(\mathrm{PVN})$, were used as a reference. PVN and SON samples were then dispensed into $1.5 \mathrm{ml}$ tubes and kept on dry ice within the cryostat. Total RNA was extracted from punched samples by combining Qiazol Reagent with Qiagens RNeasy kit protocols (Qiagen). The punched samples were removed from dry ice and rapidly resuspended, by vortexing, in $1 \mathrm{ml}$ Qiazol reagent. 
Following Qiazol phase separation with chloroform, $350 \mu \mathrm{l}$ of the upper aqueous phase was removed, mixed with $350 \mu \mathrm{l} 70 \%$ (v/v) ethanol and applied to RNeasy columns. The remaining steps were performed as recommended by the manufacturer. For cDNA synthesis, 200 ng of total RNA was reverse transcribed using the Quantitect reverse transcription kit (Qiagen).

For in vitro studies, the culture medium was removed and the cells were lysed in $350 \mu \mathrm{l}$ Qiazol Reagent (Qiagen). The lysate was mixed with $350 \mu \mathrm{l}$ absolute ethanol and added directly into the Direct-zol ${ }^{\mathrm{Tm}}$ RNA MiniPrep columns (Zymo research; R2052) and extraction continued following the manufacturer's protocol. For cDNA synthesis, $500 \mathrm{ng}$ of total RNA was reverse transcribed using the Quantitect reverse transcription kit (Qiagen).

\section{Real-time quantitative PCR analysis}

Primers for rat Creb3l1 (5'-GAGACCTGGCCAGAGG ATAC-3' and 5'-GTCAGTGAGCAAGAGAACGC-3'), rat Avp mRNA (5'-TGCCTGCTACTTCCAGAACTGC3 ' and 5'-AGGGGAGACACTGTCTCAGCTC-3'), rat $A v p$ heteronuclear RNA (hnAvp) (5'-GAGGCAAGAG GGCCACATC-3' and 5'-CTCTCCTAGCCCATGACCC TT-3'), rat c-Fos (5'-AGCATGGGCTCCCCTGTCA-3' and 5'-GAGACCAGAGTGGGCTGCA-3'), rat Rpl19 (5'-GCGTCTGCAGCCATGAGTA and 5'-TGGCATTG GCGATTTCGTTG-3'), mouse $c$-Fos (5'-TCCCCAAAC TTCGACCATGA-3' and 5'-GGCTGGGGAATGGTAG TAGG-3'), mouse Creb3l1 (5'-ACAAACTGCAGGGGA CATCA-3' and 5'-GAGCTTGGTGGGGATAGGG-3') and mouse Gapdh (5'-CAACTCCCACTCTTCCACCT3' and 5'-CTTGCTCAGTGTCCTTGCTG-3') were synthesised by European MWG Operon. The optimisation and validation of primers was performed using standard $\mathrm{ABI}$ protocols. The cDNA from reverse transcriptase reaction was used as a template for subsequent PCRs, which were carried out in duplicate. Quantitative PCR was conducted in $12.5 \mu \mathrm{l}$ reaction volumes using SYBR green master mix buffer (Roche) using an ABI StepOnePlus real time PCR system. For relative quantification of gene expression the $2^{-\Delta \Delta C T}$ method was employed [48]. The internal control gene used for these analyses were the housekeeping genes Rpl19 and Gapdh.

\section{Immunofluorescence}

Rats were deeply anesthetised with sodium pentobarbitone $(100 \mathrm{mg} / \mathrm{kg}$ i.p.) and transcardially perfused with $0.1 \mathrm{M}$ phosphate buffered saline (PBS, $\mathrm{pH}$ 7.4) followed by $4 \%(\mathrm{w} / \mathrm{v})$ paraformaldehyde (PFA) in PBS. Brains were removed and post-fixed overnight in $4 \%(\mathrm{w} / \mathrm{v})$ PFA followed by $30 \%(\mathrm{w} / \mathrm{v})$ sucrose prepared in PBS. Coronal sections $(40 \mu \mathrm{m})$ of the forebrain were cut on a cryostat and washed in PBS three times. Sections then were blocked in $5 \%(\mathrm{v} / \mathrm{v})$ horse serum prepared in PBS with
$0.25 \%(\mathrm{v} / \mathrm{v})$ TritonX-100 (PBST) for $30 \mathrm{~min}$ and then incubated with goat anti-N-terminal CREB3L1 antibody (1:250; R\&D systems, AF4080) and mouse monoclonal antibody recognising AVP neurophysin-II (NP-II, PS41; 1:200) [49] prepared in $1 \%$ horse serum/PBST at $4{ }^{\circ} \mathrm{C}$ for $48 \mathrm{~h}$. The sections were washed three times in PBS for $5 \mathrm{~min}$ and incubated with 1:500 dilution of anti-goat IgG-biotinylated secondary antibody in $1 \%$ horse serum/ PBST for $1 \mathrm{~h}$ at room temperature. Sections were washed three times for $5 \mathrm{~min}$ with PBS and incubated for $1 \mathrm{~h}$ with secondary antibodies conjugated with fluorophore (1:500 in $1 \%$ horse serum/PBST; Alexa Fluor 488 streptavidinconjugated and Alexa Fluor 594 donkey anti-mouse IgG (Invitrogen)). After three washes with PBS, sections were mounted onto glass slides with $0.5 \%(\mathrm{w} / \mathrm{v})$ gelatin, and sealed with VectorShields hard mounting media (Vector Laboratories Ltd.). For organotypic culture, the tissues on Millicell Cell Culture Insert were fixed with $4 \%$ (w/v) PFA in PBS for $20 \mathrm{~min}$ and washed three times with PBS for $5 \mathrm{~min}$. Tissues then were blocked and incubated with antibodies as described above. Images were captured on fluorescent microscope and confocal microscope (Leica). The specificity of anti-N-terminal CREB3L1 antibody in immunofluorescent staining was previously validated [20].

\section{Protein extraction and immunoblotting}

Cells were washed twice with cold PBS pH 7.4 (Gibco; 10010-015), and harvested by scraping into RIPA buffer (1 \% (w/v) IGEPAL CA-630 (Sigma I3021), $0.5 \%(w / v)$ sodium deoxycholate, and $0.1 \%(\mathrm{w} / \mathrm{v})$ sodium dodecyl sulfate (SDS) prepared in PBS) supplemented with $1 \mathrm{mM}$ PMSF and Protease Inhibitor Cocktail (Sigma; P8340). The lysate was incubated on ice for $15 \mathrm{~min}$ with vortexing every $5 \mathrm{~min}$, followed by centrifugation at $10,000 \times \mathrm{g}$ for $10 \mathrm{~min}$. Supernatants were collected and kept at $-80{ }^{\circ} \mathrm{C}$. For cytosolic and nuclear protein extraction, cells were harvested in $500 \mu \mathrm{l}$ hypotonic buffer solution (for $5 \times 10^{6}$ cells ; $20 \mathrm{mM}$ Tris- $\mathrm{HCl}$, pH 7.4, $10 \mathrm{mM} \mathrm{NaCl}, 3 \mathrm{mM} \mathrm{MgCl}$ ) supplemented with $1 \mathrm{mM}$ PMSF and Protease Inhibitor Cocktail, then moved to $1.5 \mathrm{ml}$ tube and gently resuspended by pipetting before being incubated on ice for $15 \mathrm{~min} .25 \mu \mathrm{l}$ of $10 \%$ IGEPAL CA- 630 was added to the lysate and vortexed for $10 \mathrm{sec}-$ onds. The lysate was centrifuged at $1,000 \times \mathrm{g}$ at $4{ }^{\circ} \mathrm{C}$ for $10 \mathrm{~min}$, and the supernatant was collected as the cytosolic protein. The pellet was resuspended in $50 \mu \mathrm{l}$ of Cell Extraction Buffer (100 mM Tris, pH 7.4, $2 \mathrm{mM} \mathrm{Na}_{3} \mathrm{VO}_{4}$, $100 \mathrm{mM} \mathrm{NaCl}, 1 \%$ (v/v) Triton X-100, 1 mM EDTA, $10 \%$ (v/v) glycerol, $1 \mathrm{mM}$ EGTA, $0.1 \%(\mathrm{w} / \mathrm{v})$ SDS, $1 \mathrm{mM} \mathrm{NaF}, 0.5 \%$ (w/v) deoxycholate, $20 \mathrm{mM} \mathrm{Na}{ }_{4} \mathrm{P}_{2} \mathrm{O}_{7}$, supplemented with $1 \mathrm{mM}$ PMSF and Protease Inhibitor Cocktail) and incubated on ice for $30 \mathrm{~min}$ with vortexing at $10 \mathrm{~min}$ intervals. The lysate was centrifuged at $14,000 \times \mathrm{g}$ at $4{ }^{\circ} \mathrm{C}$ for $30 \mathrm{~min}$, and the supernatant was 
collected as the nuclear fraction. Protein concentrations were determined using the Bradford assay (Bio-Rad).

For immunoblotting, proteins were separated by SDSPAGE and transferred to $0.45 \mu \mathrm{m}$ PVDF membranes (Millipore). The membranes were blocked with $5 \%(\mathrm{w} / \mathrm{v})$ skimmed-milk prepared in Tris-buffered saline- $0.05 \%$ Tween 20 (TBS-T) for $1 \mathrm{~h}$ at room temperature, followed by incubation with primary antibody diluted in $3 \%(\mathrm{w} / \mathrm{v})$ skimmed-milk in TBS-T at $4{ }^{\circ} \mathrm{C}$ overnight. This was followed by incubation with appropriate secondary antibody conjugated with horseradish peroxidase (HRP) at room temperature for $1 \mathrm{~h}$. Signal was visualised using high sensitivity WESTAR EtaC or WESTAR SuperNova extreme sensitivity HRP Detection Substrate (Cyanagen). Primary antibodies used: a goat polyclonal anti-N-terminal CREB3L1 (1:1,000; R\&D systems, AF4080) and a mouse polyclonal anti-GAPDH (1:20,000; Santa Cruz, sc-32233). Secondary antibodies used: rabbit anti-Goat IgG (whole molecule)-peroxidase antibody (Sigma: A5420) and rabbit anti-Mouse IgG (whole molecule)-Peroxidase antibody (Sigma: A9044). The specificity of anti-Nterminal CREB3L1 antibody in immunoblot assay was previously validated [20].

\section{Luciferase assays}

For luciferase assays, we used $1 \mathrm{~kb}$ rat $A v p$ promoter luciferase reporter construct cloned into pGL3 vector (Promega) as described previously [20]. AtT20 cells were seeded onto 12-well tissue culture plates. Next day, plasmids $(1 \mu \mathrm{g}$ pGL3-Avp promoter and $0.1 \mu \mathrm{g}$ pRL-TK vector/ well) were transfected into cells using lipofectamine LTX with Plus transfection reagent (Life Technologies) following the manufacturer's protocol. For chemical treatments, the culture medium was replaced with fresh medium containing $10 \mu \mathrm{M}$ FSK or DMSO (vehicle) $24 \mathrm{~h}$ after transfection. For DEX treatment, the cells were pre-treated with DMSO or 100nM DEX for $2 \mathrm{~h}$ followed by treatment with $10 \mu \mathrm{M}$ FSK or DMSO for $4 \mathrm{~h}$. Cells were harvested at appropriate time points. Luciferase assays were performed using the Promega Dual-Luciferase ${ }^{\circ}$ Reporter Assay. Luciferase activity was measured in triplicate using a Lumat LB 9507 Luminometer (Berthold Technologies).

\section{Statistical analysis}

All data are expressed as the mean + SEM. Statistical differences between experimental groups were evaluated using independent sample unpaired Student's $t$-tests or One-way ANOVA with Tukey post test (for comparison of more than 2 groups). Two-way ANOVA with Bonferonni post hoc test was used to determine interactions between two independent variables on the dependent variable. If Bartlett's test for equal variances has $p<0.01$ in One-way ANOVA, data was log transformed before analysis. $p<0.05$ was considered significant.

\section{Abbreviations}

AVP: Arginine vasopressin; CREB: CAMP responsive element-binding protein; DEX: Dexamethasone; FSK: Forskolin; hnRNA: heteronuclear RNA; MCN: Magnocellular neuron; NP-II: Neurophysin-II; PVN: Paraventricular nucleus; RIP: Regulated intra-membrane proteolysis; SCN: Suprachiasmatic nucleus; shRNA: small hairpin RNA; SON: Supraoptic nucleus.

\section{Competing interests}

The authors declare no competing financial or non-financial interests.

\section{Authors' contributions}

MG carried out cell culture, organotypic culture and molecular studies, participated in the design of the study, performed the statistical analysis and drafted the manuscript. MPG established knockdown cell line, carried out animal studies, participated in organotypic culture and helped to draft the manuscript. ASM participated in animal experiment and participated in design of the study. SYL, performed luciferase assay. JAR, JFRP and DM conceived of the study, and participated in its design and coordination and helped to draft the manuscript. All authors read and approved the final manuscript.

\section{Acknowledgements}

We gratefully acknowledge the support of the MRC (G0700954, DM), BBSRC (BB/G006156/1, MPG, JP, DM; BB/J015415/1, MG, JP, DM), University of Malaya (HIR award H-20001-E0000865, ASM, SYL, DM), and Sao Paulo Research Foundation FAPESP (2011/52108-4, JAR; 2013/09799-1, JAR).

We would like to thank Prof. Harold Gainer (NINDS, NIH, USA) for providing us with antibodies recognising AVP NP-II.

\section{Author details}

${ }^{1}$ School of Clinical Sciences, University of Bristol, Dorothy Hodgkin Building, Whitson Street, Bristol BS1 3NY, England. ${ }^{2}$ School of Medicine of Ribeirão Preto, University of São Paulo, Ribeirão Preto, Brazil. ${ }^{3}$ Department of Physiology, University of Malaya, Kuala Lumpur 50603, Malaysia. ${ }^{4}$ Department of Physiological Sciences, Biology Institute, Federal Rural University of Rio de Janeiro, Seropedica, Rio de Janeiro, Brazil. ${ }^{5}$ School of Physiology and Pharmacology, University of Bristol, Bristol BS8 1TD, England.

Received: 21 August 2015 Accepted: 18 October 2015 Published online: 26 October 2015

\section{References}

1. Burbach JP, Luckman SM, Murphy D, Gainer H. Gene regulation in the magnocellular hypothalamo-neurohypophysial system. Physiol Rev. 2001;81(3):1197-267.

2. Bourque $\mathrm{CW}$. Central mechanisms of osmosensation and systemic osmoregulation. Nat Rev Neurosci. 2008;9(7):519-31. doi:10.1038/nrn2400.

3. McKinley MJ, McAllen RM, Davern P, Giles ME, Penschow J, Sunn N et al. The sensory circumventricular organs of the mammalian brain. Adv Anat Embryol Cell Biol. 2003;172:III-XII, 1-122, back cover.

4. Boone M, Deen PM. Physiology and pathophysiology of the vasopressinregulated renal water reabsorption. Pflugers Arch. 2008;456(6):1005-24. doi:10.1007/s00424-008-0498-1.

5. Schmale $H$, Heinsohn S, Richter D. Structural organization of the rat gene for the arginine vasopressin-neurophysin precursor. EMBO J. 1983;2(5):763-7.

6. Hu SB, Tannahill LA, Lightman SL. Regulation of arginine vasopressin mRNA in rat fetal hypothalamic cell culture. Role of protein kinases and glucocorticoids. J Mol Endocrinol. 1993;10(1):51-7.

7. Shiromani PJ, Magner M, Winston S, Charness ME. Time course of phosphorylated CREB and Fos-like immunoreactivity in the hypothalamic supraoptic nucleus after salt loading. Brain Res Mol Brain Res. 1995;29(1):163-71. doi:0169328X94002427.

8. Carter DA, Murphy D. Cyclic nucleotide dynamics in the rat hypothalamus during osmotic stimulation: in vivo and in vitro studies. Brain Res. 1989:487(2):350-6. doi:0006-8993(89)90839-1.

9. Ceding P, Schilling K, Schmale H. Vasopressin Expression in Cultured Neurons is Stimulated by Cyclic AMP. J Neuroendocrinol. 1990;2(6):859-65. doi:10.1111/j.1365-2826.1990.tb00652.x JNE859.

10. Iwasaki Y, Oiso Y, Saito H, Majzoub JA. Positive and negative regulation of the rat vasopressin gene promoter. Endocrinology. 1997;138(12):5266-74. 
11. Lubelski D, Ponzio TA, Gainer H. Effects of A-CREB, a dominant negative inhibitor of CREB, on the expression of c-fos and other immediate early genes in the rat SON during hyperosmotic stimulation in vivo. Brain Res. 2012;1429:18-28. doi:10.1016/j.brainres.2011.10.033. S0006-8993(11)01962-7.

12. Carter DA, Murphy D. Regulation of c-fos and c-jun expression in the rat supraoptic nucleus. Cell Mol Neurobiol. 1990;10(3):435-45.

13. Luckman SM, Dye S, Cox HJ. Induction of members of the Fos/Jun family of immediate-early genes in identified hypothalamic neurons: in vivo evidence for differential regulation. Neuroscience. 1996;73(2):473-85. doi:0306-4522(96)00076-0.

14. Yoshida M, Iwasaki Y, Asai M, Takayasu S, Taguchi T, Itoi K, et al. Identification of a functional AP1 element in the rat vasopressin gene promoter. Endocrinology. 2006;147(6):2850-63. doi:10.1210/en.2005-1222.

15. Kiss JZ, Mezey E, Skirboll L. Corticotropin-releasing factor-immunoreactive neurons of the paraventricular nucleus become vasopressin positive after adrenalectomy. Proc Natl Acad Sci U S A. 1984;81(6):1854-8.

16. Suemaru S, Hashimoto K, Ogasa T, Takao T, Ota Z, Hirakawa M, et al. Effects of hyperosmotic stimulation and adrenalectomy on vasopressin mRNA levels in the paraventricular and supraoptic nuclei of the hypothalamus: in situ hybridization histochemical analysis using a synthetic oligonucleotide probe. Acta Med Okayama. 1990;44(5):233-41.

17. Kovacs KJ, Foldes A, Sawchenko PE. Glucocorticoid negative feedback selectively targets vasopressin transcription in parvocellular neurosecretory neurons. J Neurosci. 2000;20(10):3843-52. 20/10/3843.

18. Durlo FV, Castro M, Elias LL, Antunes-Rodrigues J. Interaction of prolactin, ANPergic, oxytocinergic and adrenal systems in response to extracellular volume expansion in rats. Exp Physiol. 2004;89(5):541-8. doi:10.1113/ expphysiol.2004.027243.

19. Berghorn KA, Knapp LT, Hoffman GE, Sherman TG. Induction of glucocorticoid receptor expression in hypothalamic magnocellular vasopressin neurons during chronic hypoosmolality. Endocrinology. 1995;136(2):804-7. doi:10.1210/endo.136.2.7835313.

20. Greenwood M, Bordieri L, Greenwood MP, Rosso Melo M, Colombari DS,

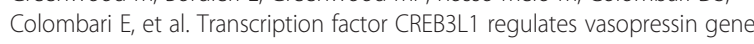
expression in the rat hypothalamus. J Neurosci. 2014;34(11):3810-20. doi:10.1523/JNEUROSCI.4343-13.2014 34/11/3810.

21. Murakami T, Kondo S, Ogata M, Kanemoto S, Saito A, Wanaka A, et al. Cleavage of the membrane-bound transcription factor OASIS in response to endoplasmic reticulum stress. J Neurochem. 2006;96(4):1090-100. doi:10.1111/j.1471-4159.2005.03596.xJNC3596.

22. Delidaki M, Gu M, Hein A, Vatish M, Grammatopoulos DK. Interplay of cAMP and MAPK pathways in hCG secretion and fusogenic gene expression in a trophoblast cell line. Mol Cell Endocrinol. 2011;332(1-2):213-20. doi:10.1016/ j.mce.2010.10.013.

23. Ginty DD, Glowacka D, Bader DS, Hidaka H, Wagner JA. Induction of immediate early genes by $\mathrm{Ca} 2+$ influx requires CAMP-dependent protein kinase in PC12 cells. J Biol Chem. 1991;266(26):17454-8.

24. Kuwahara S, Arima H, Banno R, Sato I, Kondo N, Oiso Y. Regulation of vasopressin gene expression by CAMP and glucocorticoids in parvocellular neurons of the paraventricular nucleus in rat hypothalamic organotypic cultures. J Neurosci. 2003;23(32):10231-7. 23/32/10231.

25. Emanuel RL, Girard DM, Thull DL, Majzoub JA. Regulated expression of vasopressin gene by CAMP and phorbol ester in primary rat fetal hypothalamic cultures. Mol Cell Endocrinol. 1992;86(1-2):29-36. doi:0303-7207(92)90172-3

26. Pardy K, Adan RA, Carter DA, Seah V, Burbach JP, Murphy D. The identification of a cis-acting element involved in cyclic 3',5'-adenosine monophosphate regulation of bovine vasopressin gene expression. J Biol Chem. 1992;267(30):21746-52.

27. Ma XM, Levy A, Lightman SL. Rapid changes in heteronuclear RNA for corticotrophin-releasing hormone and arginine vasopressin in response to acute stress. J Endocrinol. 1997;152(1):81-9.

28. Yue C, Mutsuga N, Scordalakes EM, Gainer H. Studies of oxytocin and vasopressin gene expression in the rat hypothalamus using exon- and intron-specific probes. Am J Physiol Regul Integr Comp Physiol. 2006;290(5):R1233-41. doi:10.1152/ajpregu.00709.2005.

29. Arima $H$, Baler $R$, Aguilera G. Fos proteins are not prerequisite for osmotic induction of vasopressin transcription in supraoptic nucleus of rats. Neurosci Lett. 2010;486(1):5-9. doi:10.1016/j.neulet.2010.09.030. S0304-3940(10)01233-4.

30. Kondo S, Murakami T, Tatsumi K, Ogata M, Kanemoto S, Otori K, et al. OASIS, a CREB/ATF-family member, modulates UPR signalling in astrocytes. Nat Cell Biol. 2005;7(2):186-94. doi:10.1038/ncb1213.
31. Murakami T, Saito A, Hino S, Kondo S, Kanemoto S, Chihara K, et al. Signalling mediated by the endoplasmic reticulum stress transducer OASIS is involved in bone formation. Nat Cell Biol. 2009;11(10):1205-11. doi:10.1038/ncb1963.

32. Saito A, Kanemoto S, Kawasaki N, Asada R, Iwamoto H, Oki M, et al. Unfolded protein response, activated by OASIS family transcription factors, promotes astrocyte differentiation. Nat Commun. 2012;3:967. doi:10.1038/ ncomms1971.

33. Vellanki RN, Zhang L, Volchuk A. OASIS/CREB3L1 is induced by endoplasmic reticulum stress in human glioma cell lines and contributes to the unfolded protein response, extracellular matrix production and cell migration. PLoS One. 2013;8(1):e54060. doi:10.1371/journal.pone.0054060. PONE-D-12-23970.

34. Greenwood M, Greenwood MP, Paton JF, Murphy D. Transcription Factor CREB3L1 Regulates Endoplasmic Reticulum Stress Response Genes in the Osmotically Challenged Rat Hypothalamus. PLoS One. 2015;10(4):e0124956. doi:10.1371/journal.pone.0124956. PONE-D-15-06018.

35. Greenwood MP, Greenwood M, Paton JF, Murphy D. Control of Polyamine Biosynthesis by Antizyme Inhibitor 1 is Important for Transcriptional Regulation of Arginine Vasopressin in the Male Rat Hypothalamus. Endocrinology. 2015:en20151074. doi:10.1210/en.2015-1074.

36. Kawasaki M, Yamaguchi K, Saito J, Ozaki Y, Mera T, Hashimoto H, et al. Expression of immediate early genes and vasopressin heteronuclear RNA in the paraventricular and supraoptic nuclei of rats after acute osmotic stimulus. J Neuroendocrinol. 2005;17(4):227-37. doi:10.1111/j.13652826.2005.01297.x. JNE1297.

37. Kondo S, Hino SI, Saito A, Kanemoto S, Kawasaki N, Asada R, et al. Activation of OASIS family, ER stress transducers, is dependent on its stabilization. Cell Death Differ. 2012;19(12):1939-49. doi:10.1038/cdd.2012.77.

38. Burke ZD, Ho MY, Morgan H, Smith M, Murphy D, Carter D. Repression of vasopressin gene expression by glucocorticoids in transgenic mice: evidence of a direct mechanism mediated by proximal 5 ' flanking sequence. Neuroscience. 1997;78(4):1177-85. doi:S0306452296006033.

39. Mohr E, Richter D. Sequence analysis of the promoter region of the rat vasopressin gene. FEBS Lett. 1990;260(2):305-8.

40. Yoshida M. Gene regulation system of vasopressin and corticotropinreleasing hormone. Gene Regul Syst Bio. 2008;2:71-88.

41. Kim JK, Summer SN, Wood WM, Schrier RW. Role of glucocorticoid hormones in arginine vasopressin gene regulation. Biochem Biophys Res Commun. 2001;289(5):1252-6. doi:10.1006/bbrc.2001.6114.

42. Watanabe $H$, Orth DN, Toft DO. Glucocorticoid receptors in mouse pituitary tumor cells. II. Nuclear binding. Biochemistry. 1974;13(2):332-7.

43. Ratman D, Vanden Berghe W, Dejager L, Libert C, Tavernier J, Beck IM, et al. How glucocorticoid receptors modulate the activity of other transcription factors: a scope beyond tethering. Mol Cell Endocrinol. 2013;380(1-2):41-54. doi:10.1016/j.mce.2012.12.014

44. Davis LG, Arentzen R, Reid JM, Manning RW, Wolfson B, Lawrence KL, et al. Glucocorticoid sensitivity of vasopressin mRNA levels in the paraventricular nucleus of the rat. Proc Natl Acad Sci U S A. 1986;83(4):1145-9.

45. Ruginsk SG, Lopes Da Silva A, Ventura RR, Elias LL, Antunes-Rodrigues J. Central actions of glucocorticoids in the control of body fluid homeostasis: review. Braz J Med Biol Res. 2009;42(1):61-7.

46. Nahar J, Haam J, Chen C, Jiang Z, Glatzer NR, Muglia $\sqcup$ et al. Rapid NonGenomic Glucocorticoid Actions in Male Mouse Hypothalamic Neuroendocrine Cells Are Dependent on the Nuclear Glucocorticoid Receptor. Endocrinology. 2015:en20151273. doi:10.1210/en.2015-1273.

47. House SB, Thomas A, Kusano K, Gainer H. Stationary organotypic cultures of oxytocin and vasopressin magnocellular neurones from rat and mouse hypothalamus. J Neuroendocrinol. 1998;10(11):849-61.

48. Livak KJ, Schmittgen TD. Analysis of relative gene expression data using real-time quantitative PCR and the 2(-Delta Delta C(T)) Method. Methods. 2001;25(4):402-8. doi:10.1006/meth.2001.1262.

49. Ben-Barak Y, Russell JT, Whitnall MH, Ozato K, Gainer H. Neurophysin in the hypothalamo-neurohypophysial system. I. Production and characterization of monoclonal antibodies. J Neurosci. 1985;5(1):81-97. 